\title{
Age Periods Of Human Life
}

\author{
Akhmet Dyussenbayev \\ Institute of physiology of man and animals of the Ministry of education and science, \\ Republic of Kazakhstan
}

\begin{abstract}
In 2015, the World Health Organization under the United Nations officially revised the age standards. A person is now considered young before 44 years of age. According to the new age classification, the young age is from 25 to 44, middle age is 44-60, elderly age is $60-75$, senile age is $75-90$ and long-livers are after 90 . This international standard is made without taking into account the objective regularities of the development physiology and psychology throughout the whole life in the course of rapid growth in youth, smooth development in mature age and the subsequent gradual aging of the human body.
\end{abstract}

Keywords: periods of life, infancy, childhood, youth, maturity, old age, long-livers, development physiology.

From the earliest times, people lay special emphasis on the milestone anniversaries of ages of $20,25,30,40,50,60,70,75$ and so on. All kinds of jubilee celebrations and events are held on this occasion. But, in fact, the generally accepted "zero" and "five" dates do not fully correspond to the real stages of human life, the stages of biological and social maturity. The age stereotypes established in our society are not expedient in all aspects.

The most relevant criterion in this issue is the 12-years chronological segment of the lunar calendar. The full cycle of the lunar calendar consists of 12 years. It is linked to the movement of Jupiter, which completely passes the circle of Zodiac for 12 years. Here, from ancient times, every year is strictly symbolically marked with the name of a particular animal having a certain meaning. Years: "mouse", "cow", "snow leopard", "hare", "wolf/dragon", "snake", "horse”, "sheep", "monkey", "chicken", "dog" and "boar". Since the last centuryalunar calendar has become more in-demand and now the interest to it is growing all over the world.

The attitude towards age among different people was developing in different ways. The differentiation of ages and the peculiarities imposed by it on the relations between people are present in all countries. The problem in question, with all seeming banality, excited scientists at all times. V.G. Belinsky asserted in this regard: "A man has its epochs of growth, not complying with which, any development in it can be put out".

Psycho-physiological changes from one stage of life to another can be seen, as the saying runs, with the naked eye. There is a correlation - interrelationship between the age of a person and his temperament, character type and the style of behavior. Under optimal conditions, the young people's character is predominantly formed by 17 years of age. Achievement of personhood comes at 25 years of age. Three key periods of life correspond to three typological groups of characters: impulsive - youth, conformal - maturity and critical - old age. Impulsive type is assertive, active, energetic. The conformal type is flexible, pliable, cautious. Critical type is principled, picky, rational. 
As this is a model, the question here is about tendencies, and the borders of age periods and stages are conditional with insignificant fluctuations. This is a kind of ideal to which a person shouldstriveto the best of his/her abilities.

\section{Infancy Period}

Only one year is given to the most expressive, that is, a loud, noisy, tearful and hysterical period of life, but this is a most intensive time period of youth. During infancy: only $\mathbf{1}$ year from the moment of birth a child grows and develops extremely quickly, and this infancy - including the intrauterine period being studied by the independent science of embryology - is in its importance is equivalent to the subsequent $12^{\text {th }}$ years of age. With reference to this question, $A$. Schopenhauer noted very aptly: "Hours of the boy are longer than the days of the old man".

\section{Childhood Period}

In the childhood, there is the highest general physical activity from $\mathbf{1}$ to $\mathbf{1 3}$ years of age. We can conventionally split it into three stages: nursery (1-3 years), kindergarten (3-7 years) and elementary school (7-13 years) when the mental emotionality gradually decreases and infancy dynamism becomes already more conscious and less subconscious than before. Ambrose Bierce has quoted in an original way in this regard: "Childhood: the period of human life intermediate between the idiocy of infancy and the folly of youth - two removes from the sin of manhood and three from the remorse of age".

\section{Period Of Youth}

In the mobile youth from 13 to 25 years of age, while the high dynamism of the psyche is still present, but nevertheless, the plasticity of the psyche is stealthily and graduallystealing up. At this time, two valuable properties of the character match up perfectly: impulsiveness and conformality. This period also consists of three stages: adolescence (13-17 years), youth (17-21 years) and the crown of youth (21-25 years). If the first stage is dominated by dynamism of the psyche, then on the third stage, its plasticity prevails. Mark Twain said: "When I was a boy of fourteen, my father was so ignorant I could hardly stand to have the old man around. But when I got to be twenty-one, I was astonished at how much he had learned in seven years".

According to physiological and psychological parameters, around half of the overall development of mental abilities in children occurs in the first three years of life, one third between three and seven years, the rest - between seven and seventeen years. These years are not less important for the formation of an emotional sphere for the whole subsequent life. Ideally, the meaning of a person's life is not in the number of years lived, but in creative works to the benefit of others.

This is evidenced by the life of remarkable people. For instance, Joan of Arclived for 19 years, Evariste Galois - 21 years.

\section{Maturity Stage}

It consists of three periods: the beginning of maturity, the midst of maturity and the end of maturity. At a mature age, from 25 to 61, the body reaction, the speed of physical processes is markedly inferior to the previous period, but there is more rationality and more pliability in the behavior strategy than in youth. A person becomes more cautious, reserved and attentive, although somewhat evasive, and begins to confidently use his/her own life experience. When the sunset of youth sets in, then the dawn of maturity comes. 


\section{The Period Of Beginning Of Maturity}

The initial period of maturity of 25-37 years of age is more characterized by the combination of a high dynamism of mental processes with behavior pliability, or, to put it another way, there is an obvious plastic manifestation of the psyche. This stage is most productive in terms ofcreation. This is exactly the age when gifted people most often experience the rise of unbridled intellectual abilities. A vivid example of this is the life and work of great people.

The following people did not overcome the popularly so-called "fateful age*": Niels Abel lived 26 years, M.Yu. Lermontov (26), Ch.Ch. Valikhanov (29), Bruce Lee (32), Alexander the Great (32), Yu.A. Gagarin (34), Wolfgang Amadeus Mozart (35), George Gordon Byron (36), Heinrich Hertz (36), Sadi Carnot (36), Marilyn Monroe (36), Diane Spencer (36).

\section{The Period Of The Midst of Maturity}

For the middle period of maturity at 37-49 years of age, the compromise behavior is mostly typical. This is the "golden time", when a person has accumulated enough knowledge, life experience, professional skills and reached the peak of his/her potential abilities. This is a peak of social maturity and career, the age of really deft leaders.

The following people did not reach age of half a century: Vincent Van Gogh lived 37 years, Arthur Rambo (37), A.S. Pushkin (37), Blaise Pascal (39), Ernesto Che Guevara (39), Jack London (40), John Lennon (40), Fernan Magellan (40), Joe Dassin (42), Johann Schiller (45), Pierre Curie (46), Albert Camus (46), John Kennedy (46), Simon Bolivar (47), Horatio Nelson (47), Edith Piaf (47).

\section{The Period of The End of Maturity}

The period of full maturity, that is, a considerable age of 49-61 is more characterized by still flexible, but somewhat sluggish behavior, that is, the sub-plasticity of the psyche. In fact, this is the post-culminating stage, when a person becomes less convinced and more cautious than before, acquires staidness and external solidity, begins to look back nostalgically for the first time, recall the irretrievable years of youth, and moreover in some cases trying to act like impulsive young people.

The following people lived for around half a century: Thomas Aquinas lived 49 years, James Cook (50), Michael Jackson (50), Napoleon I Bonaparte (51), Jean-Baptiste Molière (51), Honore de Balzac (51), William Shakespeare (57), Christopher Columbus (54), Ludwig Beethoven (56), Abraham Lincoln (56), Steve Jobs (56), Thomas More (57), Jeffrey Chaucer (57), Charles Dickens (58) ), George Harrison (58), Heinrich Heine (58), Gustave Flaubert (58), Stendhal (59), Oliver Cromwell (59), Richard Arkwright (59).

\section{Presenile Period}

The tactical behavior among the elderly people of 61-73 years of age. During this time a person is inclined to teach others, to philosophize and even too much at times. Sometimes these "wise men" are even left by their own children so that the old people involuntarily reach out for their grandchildren. On the other hand, people really accumulate a lot of knowledge and great life experienceby these years. This is the venerable age and such people deserve respect in the family and society. But, being"unofficial" people, from the outside they look intrusive in a way. 
To label all people of this and later ages as conservative is groundless. Conservatism manifests itself in people of all ages and is predetermined not only by psychological peculiarities. Discretion and caution should not be confused with it.

The following people lived on Earth: Georg Hegel 61, Andre-Marie Ampere (61), Luigi Galvani (61), Gregor Mendel (61), Ernest Hemingway (61), Giovanni Boccaccio (62), Robert Oppenheimer (62), Rembrandt (63 ), Alfred Nobel (63), Franklin Roosevelt (63), Karl Bosch (65), Ernest Rutherford (66), Dale Carnegie (66), Leonardo da Vinci (67), George Washington (67), Adam Smith (67) , Nicolaus Copernicus (70).

\section{Senile Period}

The senile people of 73-85 years of age are firmlyjudgmental. This is the time when a person becomes secluded, thoughtful and critical more often or self-critical more less often. The character increasingly acquires the features of a stubborn and convinced introvert, that is, a person becomes converted into his/her inner world. The high dynamism of the psychic activity is replaced with the inertia of psycho-physiological processes. This is the age of wise men - the judicious people, whose motto is "second thoughts are best!" People of this age group avoid noisy and cheerful parties as well as clothes of bright and vibrant colors. They prefer solitude;they criticize everyone, in particular, the young people, which is why they are called grumblers.

The following people lived much longer: Charles Darwin 73, Akhmet Yassawi (73), Howard Aiken (73), Alexander Fleming (73), Jawaharlal Nehru (74), Archimedes (75), Alexander Bell (75), Albert Einstein (76), Niels Bohr (77), Wilhelm Roentgen (77), John Tolkien (81), Sigmund Freud (83), Isaac Newton (84).

\section{The Elderly Period}

The elderly people older than 85-97 years of age are sentimental as a rule.Mostly depressive style of behavior characteristic oflong-liversis a mirror reflection of the expressive infancy with the opposite sign because the redundantly increased emotionality of the psyche, while fading away, changes to sensitivity, that is, being sensual and easy vulnerable, when there are no tears in eyes as it happens with infants but a fragile hypochondriac soul is crying in secretin some cases.

There are fewer and fewer of those who have been given a chance of longevity: Betty Friedan lived 85 years, James Madison (85), Zelman Waksman (85), Oscar Monet (86), Theresa Calcutta (87), Gabriel Marquez (87), Margaret Thatcher (87), Gustav Hertz (88), Charlie Chaplin (88), Akira Kurosawa (88), Max Planck (89), Winston Churchill (90), Pablo Picasso (91), Linus Pauling (93), Charles Sherrington (94), Charles Huggins (95), John Rockefeller (97).

The period of the elderly age begins at 85 and there is just a little over one "circle" - a 12-year segment cycle from this peak to 100 years of age. This is a lot of the extreme old age. The lot, which is neither easy nor simple.

According to the gerontologists' hypothesis, the maximum life expectancy can reach up to 125 years and according to the Bible - up to 120 ("And the Lord said: My Spirit will not contend with humans forever, for they are mortal; their days will be a hundred and twenty years" (Genesis $6: 3$ ). 
The periods of life fit quite accurately into the 12-year cycle of the lunar calendar, where each circle means a "segment". And if one follows this calculation, it is easy to calculate that the peak of social maturity falls on the 43rd year of life and maturity endsat 61 , the period of old age begins with 73 years of age. Apparently for this reason, the Japanese and Koreans celebrate 1 year and the jubilee in 61 not recognizing the "zero" and "five" dates.

Symbolically, the childhood ends at about 13 years old, when physiological maturity begins, one of the important criteria of which is the beginning of puberty. Youth endsat 25 years of age,and it's not just a quarter of a century, but the peak of biological maturity, which is followed by the social maturity, when a person is able to make independent decisions because the brain already has enough necessary and useful information for this.

Reduction of adult age of young people, that is, when they get out of the influence of parents from the age of 21 to 18-19 is a manifestation of a modern dynamic era. However, do children and their parents realize that over the age of 13 they are no longer little kids, that is, not children? Do young people themselves and their relativesunderstand that at the age of 25 they have already crossed the threshold of maturity? Who does a person consider himself atthe age of 50 - young, mature or old? And after 61, he/she thinks he is 73? In a busy world, we do not attach much importance to it and in a lot of families this important issue is not considered seriously. As a result, we get: the young people are at the age of 40 , children are at the age of 20, the elderly are at the age of 50. It is notable how Voltaire said: "He who has not the spirit of this age, has all the misery of it".

Parents often bate demands towards their family members by sparing them, cherishing them simply for no reason. This is nothing but a disservice, as a result of which not infrequentlywe get irresponsible overgrown children. There is only one step to the psychology of a dependent. The period of maturity, which is emphasized among all people, in particular its first stage falling on the years of the achievement of personhood (25-37 years), is most important both foran individual and society. Here it is very important to separate adulthood from pseudoadulthood, when young men or girls who have barely emerged from adolescence to pretend independentbehave deliberately freely, boldly and sometimes aggressively. The criterion of social maturity is the mastering of a certain set of social rolesby a young man, which characterize an adult.

Each person grows and develops and then grows old imperceptibly for people around, which is quite natural. Therefore, the boundaries of age periods are blurred. We usually say: 2-3 years of age - it's time for the child to go to kindergarten, 6-7 years of age - to school, 17-18 years it's time to continue studying or start working. These standards have been learned by the society a long time and there are no problems about it.

The situation is different with respect to subsequent age periods when there are no such generally accepted criteria. We have no generally accepted life stages except round dates from 17 till 63 years of age, which often leads to confusion. Children, parents, teachers and the whole society often bate demands to a personin this context. However, we often say: "You are so old and you are still a child!"which often sounds not convincing, unfounded as it is not reasoned in the form of a social standard. Therefore, it is necessary to develop a uniformage standard taking into account the achievements of gerontology so that people know at what stage of life they live, study or work. 


\section{References}

Ambrose Bierce "Devil's Dictionary" - Moscow, 2005, Publisher: Eksmo. - 544 p.

Arthur Schopenhauer "Aphorisms of worldly wisdom". - Moscow, 2013, Publisher: Azbuka. - 256 p.

V.G. Belinsky "On the education of children." Pedagogy History Chrestomathy - Moscow, 1971, Publisher: Prosveschenie. - p. 261-272.

A.R. Dyusenbayev "Key stages of human life." Popular scientific collection "Anatomy of soul", - Almaty, 2005 Publisher: IP DAR. P. 22-30.

A.R. Dyusenbayev "Seasons of life". Magazine "Science and Education of Kazakhstan", No. 4. P.62-68. - Astana, 2011.

A.R. Dyusenbayev "The main age segments." Magazine "Intellect", №6. P. 11-17. - Almaty, 2011.

A.R. Dyusenbayev "The main periods of life." Magazine "Thought", №7. P.24-29. - Almaty, 2011.

A.R. Dyusenbayev "Stages of the life cycle." Magazine "Persona", №2. P. 90-94. - Almaty, 2012.

A.R. Dyusenbayev "The significance of age periods and their peculiarities." Publisher: Russian Psychological Society "Psychological Newspaper". - St. Petersburg, June 21, 2012.

Mark Twain "The most ingenious aphorisms and quotes" - Moscow, 2013, Publisher: AST. - 160 p.

Maria Ershova "The Legend about theLunar Calendar": - St. Petersburg, 2010, Publisher: Azbuka-klassika. - 32 p.

Francois-Marie Voltaire "Miniature book of aphorisms" - Moscow, 2012, Publisher: Phoenix. - 58 p.

Note: $*-37$ years 